\title{
Kilowatt Hour
}

National Cancer Institute

\section{Source}

National Cancer Institute. Kilowatt Hour. NCI Thesaurus. Code C70436.

A non-SI unit of energy equivalent to one kilowatt of power expended during the period

of time equal to one hour. 